\title{
Health-Related Factors Influencing School Drop-Out Rate in Akoko North-East Local Government Arear of Ondo State.
}

\author{
Adeleke Olasunkanmi. R. \\ Department of Human Kinetics and Health Education \\ Adekunle Ajasin University Akungba-Akoko \\ Ondo State.Nigeria
}

Emmanuel Oluwafemi. F.

Department of Human Kinetics and Health Education

Adekunle Ajasin University Akungba-Akoko

Olaseyo Toyosi

Department of Human Kinetics and Health Education

Adekunle Ajasin University Akungba-Akoko

\begin{abstract}
This study investigated the health-related factors influencing school drop-out rate in Akoko North-East LGA of Ondo State. Two null hypothesis on the rate at which adolescents drop out of school for health-related reasons is not significantly higher than the rate at which they drop out for non-health related reasons. (e.g Poverty, school performance) and health-related factors responsible(Substance use/abuse, teenage pregnancy/motherhood ,Exposure to sexual harassment and communicable and non communicable disease) are not a significant factor in adolescents dropping out of school were formulated to guide the study. This study adopted the descriptive survey research design. The population of the study consist of all out-of school adolescents in Akoko North-East Local Government Area, Ondo State. The sample for this study comprised of 200 out-of-school adolescents selected from Akoko North-East LGA of Ondo State. The LGA has 13 wards, from which ten were selected using simple random sampling technique. From each ward, the snowballing technique was used to select respondents. At the initial stage of snowballing sampling, the researcher established contacts with five drop-outs from each of the ten wards through friends and relatives residing in them. Each of the respondents was implored to provide information needed to locate other adolescent(s) who were also drop-outs. The follow-up yielded other sets of drop-outs who also recommended others in their category, until 200 respondents were got. The instrument used to collect data for this study was a self-designed questionnaire. The questionnaire developed was validated by experts in the Department of Physical and Health Education who made reconstructions where necessary in order for it to measure what it was supposed to. The corrected questionnaire was used for the study. The questionnaire was administered twice to the same set of 20 school dropout adolescents who were not part of the sample for the study. There was a two week interval between the two tests. The data obtained from both tests were correlated using the Pearson Product Moment Correlation Co-efficient (PPMCC) to establish the strength of the relationship between the two sets of scores. The result showed that $r=0.82$ which was considered reliable enough to make the questionnaire reliable. Two hundred copies of the questionnaire for this study were administered by the researcher and two of his friends who acted as research assistants and who were well taught on what to do. Respondents were contacted individually at their homes, shops motor parks and hawking locations. Administration of the questionnaire was done on the spot to ensure high rate of retrieval and completed questionnaire were collected on the spot. The data collected for this study were analysed using percentage and chi-square. The result revealed that Out of 200 respondents, 156 (78\%) respondents dropped out of school for health-related issues, while only $44(22 \%)$ dropped for other reasons like financial problem, while Substance use and abuse $\left(x^{2}=36\right)$; Teenage
\end{abstract}


pregnancy/motherhood/fatherhood $\left(x^{2}=36.28\right)$, Sexual harassment (13.82) and communicable diseases $\left(x^{2}=\right.$ 32.73) are significant health-related factors influencing school dropout rate among adolescents. Consequent upon the findings, it was recommended among others, that School authorities should enact strict laws regarding sexual coercion and such laws should be strictly enforced and Schools should regularly mount counseling programmes on human sexuality to help adolescent avoid untimely sex and unwanted pregnancies and unexpected motherhood/fatherhood that can lead to dropping out of school.

Key words: Education, Adolescent, School dropout and Health related issues.

DOI: $10.7176 / \mathrm{JHMN} / 63-11$

Publication date:June $30^{\text {th }} 2019$

\section{INTRODUCTION}

Education is a tool for any nation to development. Development can only be achieved through education by ensuring that adolescent attends and complete secondary education. Unfortunately, the issue of students dropping out of school is becoming alarming in Nigeria. [1],says a drop-out is a student who on account of unforeseen circumstances cannot complete a course in secondary education for which he or she originally enrolled. Individual's right to education has been repeatedly affirmed in many organisations and conventions such as the 1948 Convention on the Rights of the Child and the 1990 World Conference on Education for All by United Nations Educational Scientific and Cultural Organization[2]. There is a general consensus that the school dropout problem has reached an epidemic proportion internationally and has become a global problem confronting the education industry round the world [3], [4] and [5]

The report of [10] on the state of the world's children showed that about 130 million children in the developing world are denied their rights to education by dropping out of school. Nigeria ranked high among these nations having approximately one out of every five children out of school with a total of 10.5 million accounting for $47 \%$ of the global total. The statistics also revealed that despite high gross enrolment, completion rates still stood at $70.6 \%$ for girls as against $80 \%$ target set, whereas, the dropout rate for boys stood at $68.2 \%$. The United Nations Educational Scientific and Cultural Organization [7] reported that, Nigeria has the highest number of school-aged pupils that are not in the classroom worldwide. In the report, Nigeria is at the top of the table of 12 problem countries that have a high school dropout rate with one in every five children not in school. Currently, a total of 10.5 million out of 76.5 million Nigerian kids are not in school, accounting for about $47 \%$ of the global total.

[8] categorized health reasons why students drop-out of school into four clusters which include; substance abuse and teenage pregnancy.[9] found out that, the decision to drop out of school often occur much closer in time to adolescents' substance use disorders and teenage pregnancy. [10] said that, substance use disorders are strongly associated with other conduct and psychiatric disorders with effects on dropout. Since the psychiatric disorders tend to occur prior to initiation of substance use, it is important to account for their effects before assessing whether or not substance use disorders are associated with additional increments of dropout risk. [11] opined that students who use one substance are also more likely to use other substances. For example, students who drink alcohol are more likely to smoke tobacco and use illicit drugs than students who do not drink. This means that associations between any one particular substance and dropout might arise from the causal effects of other substances Apart from pregnancy issues, girls contract many chronic diseases that have resulted in their inability to continue schooling.

Dropping out is not a mere problem that affects an individual only, but the entire community as well. According to [8], students who withdraw from school prematurely end up not obtaining any certificate of graduation. In addition, [12] stated that, the major social costs of dropping out of school include; reduced political participation, increased demand for social services, increased crime rates and poor levels of health. Sexually harassed individuals can suffer through a number of psychological effects ranging from irritation and frustration to anxiety, stress, and trauma as sexual harassment is often associated with assault, bullying, coercion, discrimination, favoritism, exploitation and intimidation[13].According to [14], sexual harassment is defined as unsolicited, unwelcome and unreciprocated sexual overture from a person who is not considered as sexual relation. These include any inappropriate sexual overture, subtle and unsubtle persistent behaviour, assault and actual sexual abuse that may be expressed physically, verbally or non-verbally, usually from someone with a higher power or at a vantage position to a less privileged person. Sexual harassment in schools has also been described as an unwelcome behaviour of a sexual nature that makes one feel uncomfortable, fearful or powerless, and interferes with the schoolwork. In the same vein, sexual harassment can threaten a student's physical and emotional wellbeing, influence how well a student perform in school, and make it difficult for the student to achieve her career goals [15]. As a global challenge, sexual harassment takes on various trends and nature, but most importantly, it emanates from unequal power relation that is also associated with gender based violence and violation of human rights. 
In addition, individual costs include; lower earnings, unemployment prospects and greater likelihood of health problems. It is clear from the foregoing, that by dropping out of school, students could severely limit their chances of attaining economic and social well-being in the future.

In Akoko North-East Local Government Area, where this study was carried out, it is common place to see adolescents and especially girls within the age bracket of 16 and 19 years roaming the streets without any concrete thing to do. Often, these youths engage in drug abuse, drunkenness, smoking and inhaling what they call "solution" to make them high. Many female adolescents are seen in markets, motor parks and along the streets hawking and engaging in odd jobs, while their male counterparts dominate bulk of area boys, bus conductors and motorcycle riders. Series of questions regarding the circumstances surrounding their not being in school, the proportion of adolescents dropping out of school for health reasons, health factors underlying non-school completion and a host of others could be asked. Conducting researches in order to providing answers to these questions could be a pointer to workable strategies to prevent the problem of non-school completion among the adolescents. Unfortunately, there are very few studies in this area especially in Ondo State. Therefore, there is need to carry out a scientific research on the school drop-out problem in Akoko North-East Local Government of Ondo State with the purpose of assessing the health-related factors influencing drop out among adolescents.

\section{Objectives of the study}

The following research questions were formulated to guide the conduct of the study:

(a) How prevalent is dropping out of school due to health-related reasons in Akoko North-East LGA, OndoState?

(b)What are the health-related factors responsible for male and female adolescents dropout in the study area? Research hypotheses

Hypothesis 1: The rate at which adolescents drop out of school for health-related reasons is not significantly higher than the rate at which they drop out for non-health related reasons. (e.g Poverty, school performance).

\section{Hypotheses 2:}

a. Substance use/abuse is not a significant factor in adolescents dropping out of school.

b. Teenage pregnancy/motherhood is not a significant factor in adolescents dropping out of school.

c. Exposure to sexual harassment is not a significant factor in adolescents dropping out of school.

\section{METHODOLOGY}

This study investigated the health-related factors influencing school drop-out rate in Akoko North-East LGA of Ondo State. This study adopted the descriptive survey research design. The population of the study consist of all out-of school adolescents in Akoko North-East Local Government Area, Ondo State.The sample for this study comprised of 200 out-of-school adolescents selected from Akoko North-East LGA of Ondo State. The LGA has 13 wards, from which ten were selected using simple random sampling technique. From each ward, the snowballing technique was used to select respondents. At the initial stage of snowballing sampling, the researcher established contacts with five drop-outs from each of the ten wards through friends and relatives residing in them. Each of the respondents was implored to provide information needed to locate other adolescent(s) who were also drop-outs. The follow-up yielded other sets of drop-outs who also recommended others in their category, until 200 respondents were got. The instrument used to collect data for this study was a self-designed questionnaire. The questionnaire developed was validated by experts in the Department of Physical and Health Education who made reconstructions where necessary in order for it to measure what it was supposed to. The corrected questionnaire was used for the study. The questionnaire was administered twice to the same set of 20 school dropout adolescents who were not part of the sample for the study. There was a two week interval between the two tests. The data obtained from both tests were correlated using the Pearson Product Moment Correlation Co-efficient (PPMCC) to establish the strength of the relationship between the two sets of scores. The result showed that $r=0.82$ which was considered reliable enough to make the questionnaire reliable. Two hundred copies of the questionnaire for this study were administered by the researcher and two of his friends who acted as research assistants and who were well taught on what to do. Respondents were contacted individually at their homes, shops motor parks and hawking locations. Administration of the questionnaire was done on the spot to ensure high rate of retrieval and completed questionnaire were collected on the spot. The data collected for this study were analysed using percentage and chi-square. 


\section{Hypotheses Testing}

Hypothesis (1): The rate at which adolescents drop out of school for health-related reasons is not significantly higher than the rate at which they drop out for non-health related reasons. (e.g Poverty, school performance). Data in table 3 is used to test this hypothesis

Table 6: One way Chi-square Comparing Prevalence of School Dropout for Health-Related and NonHealth-Related Reasons.

\begin{tabular}{|c|c|c|c|c|c|c|}
\hline Reasons & No & $d f$ & Cal $x^{2}$ & Crit. V & P. V & Decision \\
\hline $\begin{array}{l}\text { Health-related reasons } \\
\text { Non-health-related reasons }\end{array}$ & $\begin{array}{l}147 \\
53\end{array}$ & 1 & 60.12 & 3.84 & 0.05 & * \\
\hline
\end{tabular}

On table 6 , the $\mathrm{x}^{2}$ analysis comparing the prevalence of school dropped out for health related and nonhealth-related reasons showed that the cal. $\mathrm{x}^{2}(60.12)$ is greater than the crit. $\mathrm{x}^{2}(3.841) d f 1$ at 0.05 significance level. Therefore hypothesis 1 is rejected. This means that more adolescents drop out for health-related reasons than non-health-related reasons.

Hypotheses 2a-d:

Table 8: Chi-square Summary Table on Respondents Opinions of Health-Related Factors Causing Adolescents Dropout

\begin{tabular}{|c|l|c|c|c|c|c|c|}
\hline ITEM & \multicolumn{1}{|c|}{ H-R Factors } & No & $\boldsymbol{d} \boldsymbol{f}$ & Calc $^{\mathbf{2}}$ & Crit. V & P. V & Decision \\
\hline A. & $\begin{array}{l}\text { Substance use \& } \\
\text { abuse }\end{array}$ & 3 & 36.01 & 7.815 & & $*$ \\
B & $\begin{array}{l}\text { Teen pregnancy \& } \\
\text { fatherhood }\end{array}$ & 200 & 6 & 36.28 & 12.592 & 0.05 & $*$ \\
C & $\begin{array}{l}\text { Sexual Harassment } \\
\text { Communicable \& } \\
\text { non comm. diseases } \\
\text { Physical disability }\end{array}$ & 3 & 13.82 & 7.815 & $*$ \\
D & 3 & 32.73 & 12.592 & $*$ \\
\hline
\end{tabular}

From Table 2, the $\mathrm{x}^{2}$ calculated values of all the four health-related factors examined in this study, that is; Substance use and abuse $\left(\mathrm{x}^{2}=36.01\right) d f 3$; Also, the $\mathrm{x}^{2}$ calc. values for Teen pregnancy/motherhood/fatherhood $\left(\mathrm{x}^{2}=36.28\right) d f$ 6; Sexual harassment(13.82) df 3 were greater than crit. $\mathrm{x}^{2}$ value of 7.815 at 0.05 significance level and communicable and non communicable diseases $\left(\mathrm{x}^{2}=32.73\right) d f 3$ were greater than crit. $\mathrm{x}^{2}$ value of 12.592 at 0.05 significance level. These results indicated that factors $\mathrm{A}, \mathrm{B}, \mathrm{C}$ and $\mathrm{D}$ are significant health-related factors influencing school drop out rate among adolescents.

These results indicated that factors $\mathrm{A}, \mathrm{B}$ and $\mathrm{C}$ are significant health-related factors influencing school dropout rate among adolescents.

\section{Discussion of Findings}

In this study, result indicated that dropping out of school for health-related issues is highly prevalent. This result aligned with that of UNESCO (2010) that poor health in adolescence and childhood has been associated with higher risk of dropping out of school. This same result which did not find financial constraint as being responsible for adolescents' dropping out of school ran contrary to UNESCO (2015) submission that indicated 
lack of financial aid as a main problem causing non-school completion. However, this current findings nullified the general assumption that financial issue regarding inability to pay school fees is usually the reason why students drop-out of school.

This study established that substance use/abuse is a factor responsible for adolescents dropping out in the study area, a result that corroborated the findings of Glantz (2008) and Macleod (2010) that substance use especially marijuana is strongly associated with conduct and psychiatric disorders with effects on school performance. The result also conformed with statement of Bray and Zarkin (2014) that students who use one substance are also more likely to use other substances and excessive use of drugs which results in dependence will likely lead to, truancy, lack of time devotion to work, disinterest in school and eventually results in non school completion. Some addicts may become neurotic or psychotic having long-term effect on schooling. It also supported Hans and Chen (2012) who found out that, the decision to drop out of school often occur much closer in time to adolescents' substance use disorders and teenage pregnancy

The result of this study showed that out of 200 respondents in this study, 147 respondents dropped out of school for health-related issues and out of 147 respondents who dropped out of school because of health-related reasons as many as $85(57.82 \%)$ were females, while 62(42.18) were males. This is in line with Ajake (2012) report that dropping out of school is more prevalent Considering the singular factor of pregnancy one would agree that female will dominate dropouts who have health issues. It affirmed Hans and Chen (2012) whom opined that, the decision to drop out of school often occur much closer in time to adolescents' teenage pregnancy Ajake (2012) opined that problem of sexual coercion and contraction of various diseases may add to reasons why more girls than boys drop out of school. The few males who claimed that they dropped because they became emergency fathers could have also experienced hostility from parents for disappointing them. Many parents may even decide that the money for his schooling be diverted to nursing baby and caring for his teenage girlfriend who he impregnated.

The result showed that sexual coercion/harassment lead to high school dropout rate. Though, the finding was supported by McElroy (2006) and Ribar (2015) that sexual coercion may deter the adolescent from achieving her career goal and Moronkola and Oyebami (2007) that sexually harassed individuals can be frustrated, but to this researcher, felt that such frustration should not be enough for any serious student to o drop out of school. This researcher believe that once the case is reported and the school authority takes prompt actions on it, the harassed should feel more secured to remain in school instead of deciding to drop out of school. The worst case scenario is that the harassed student may decide to change her school.

\section{Conclusion}

Based on the findings of this study, it was concluded that adolescents in Akoko North-East LGA dropped out majorly for health-related factors. Health reasons for dropping among females were teenage pregnancies and drug abuse for males. Also, pregnancy /early fatherhood and sex coercion/harassment were factors in adolescents dropping-out of school.

\section{Recommendations}

Based on the findings of the study, the following recommendations were made:

1. Schools should regularly mount counseling programmes on human sexuality to help adolescent avoid untimely sex and unwanted pregnancies and unexpected motherhood/fatherhood that can lead to dropping out of school.

2. The school curriculum should be designed to include provision of recreational facilities. This will help in diverting the attention of students from non-constructive activities like drugging, prostitution etc. to more constructive ones.

3. School authorities should enact strict laws regarding sexual coercion and such laws should be strictly enforced.

4. Lastly, the Federal as well as Local Governments should provide distance learning or part-time programmes that will provide opportunity for the school dropped out adolescents.

\section{References}

[1]. Ogunowo, R. (2015). The Desire to Remain Awake at Night Among Students of Tertiary Institutions of Nigeria: The Health Implications. International Journal of Academic Research, 2 (2): 29-33.

[2]. UNESCO, (2009). Education for all by 2015: Will we make it? Progress and Challenges in Ending the High School Dropout Epidemic. EFA global monitoring report. Retrieved in January 2015 from www.unesco.org

[3]. Wotherspoon J. (2008). School Absence and Treatment in Secondary School Children, Orfield Harvard Education Press. 
[4]. Patrick, M. (2013). Dystrophies in Higher Education: Nigerian Experience. Higher Education Review, 31(3), $17-26$

[5]. Uwadia, C. (2015). Is ICT a Sine-qua-non to Modern University Management. Being an Address delivered at 46th edition of the Business meeting of the committee of Registrars of Nigerian Universities (CORNU). May 2nd - 4th.

[6].UNESCO. (2010). The Rational for Sexuality Education: International Technical Guidance on Sexuality Education: An Evidence-informed Approach for Schools, Teachers and Health Educators. UNESCO Publications. 1\&2, 2-10

[7]. UNESCO. (2015). International Standard of Classification of Education (abridged edition) Universal Basic Education Programme (2015).Routine monitoring report. Department of Monitoring and Evaluation

[8]. Ajake, U. E. (2012). Child Rearing Styles, Premarital Sexual Practices and Drug Abuse Among Senior Secondary School Students in Cross River State, Nigeria. Medwell Journal of Social Sciences, 4 (1): 71-75.

[9]. Hans, S. \& Chen, Z. (2012), Does School Time Matter? On the impact of compulsory education age on school dropout. Economics of Education Review 30, 1384-1398.

[10]. Glantz, M. \& Anthony, J. (2008). Mental Disorders as Risk Factors for Later Substance Dependence: Estimates of Optimal Prevention and Treatment Benefits. Psychological Medicine: 1-13.

[11]. Bray, J. \& Zarkin,G. (2014). The Relationship between Marijuana Initiation and Dropping out of High School. Health Economics, 9(1): 9-18.

[12]. Azam, L. (2015). Drug Abuse and Prevention. National Institute on Drug Abuse, Washington D.C

[13]. Moronkola, O. A. \& Oyebami, O. (2007). Age at Menarche, Menstrual Patterns, Sexual Health Knowledge, Attitudes and Premarital Sexual Patterns of Female Athletes in Ibadan, Nigeria. East African journal of Public Health 4 (2) 51-52.

[14]. Ribar, D. (2015). The Socioeconomic Consequences of Young Women's Childbearing: Reconciling Disparate Evidence. Journal of Population Economics, 12(4): 547-565.

[15]. McElroy, S. (2006). Early Childbearing, High School Completion, and College Enrollment: Evidence from 1980 High School Sophomores. Economics of Education Review, 15(3): 303-324.

\section{About the author}

Mr Olasunkanmi Rowland Adeleke is a certified Health Education practitioner, got his Master degree in Reproductive Health Education from Obafemi Awolowo University, Ile-Ife ,Nigeria, he has published several articles in National and International journals, presently is working as a Assistant Lecturer in Adekunle Ajasin University Akungba- Akoko Ondo State. He currently a PhD student ( Reproductive Health Education ) 